\title{
Results of SGLT2 inhibitor treatment in patients with Type 2 Diabetes mellitus and heart failure with reduced ejection fraction
}

\author{
Hatice Ozisik ${ }^{*}$, Sevki Cetinkalp ${ }^{1}$, Aytac Candemir ${ }^{3}$, Aslı Suner $^{2}$ and Sanem Nalbantgil ${ }^{3}$ \\ ${ }^{1}$ Department of Endocrinology, Ege University, İzmir, Turkey \\ ${ }^{2}$ Department of Biostatistics and Medical Informatics, Ege University, İzmir, Turkey \\ ${ }^{3}$ Department of Cardiology, Ege University, İzmir, Turkey
}

\begin{abstract}
Introduction: Type 2 diabetes mellitus (T2DM) incidence is increasing all over the world due to obesity. Heart failure (HF) occurs when the functional impairment develops in the myocardium. T2DM may concur with HF and cause its development. The excellent pleiotropic effects of SGLT2 inhibitors within the cardiovascular system make these drugs attractive for the treatment of diabetes in patients with $\mathrm{HF}$.

Materials and Methods: Our study population included 21 patients with New York Heart Association (NYHA) classification II to IV with an ejection fraction less than or equal to $40 \%$ and type 2 diabetes mellitus. They were enrolled between February 2019 and February 2020. We collected information on age, sex, eGFR, Left ventricular ejection fraction (LVEF) and duration of empagliflozin usage. Addition of once daily $10 \mathrm{mg}$ of empagliflozin to their treatment applied.

Results: 21 patients with NYHA classification II to IV with an ejection fraction less than or equal to $40 \%$ and type 2 diabetes mellitus were enrolled, 19 were male (90.5\%). The mean age of the patients was $60 \pm 7.21$ (Male: $59.11 \pm 7.15$; Female: $57.50 \pm 10.60)$. The mean use of empagliflozin was $6.90 \pm 4.38$ months. The mean LVEF in Ecocardiography was $30.52 \pm 9.36 \%$. The difference between pro BNP ( $p=0.205)$, total cholesterol ( $p=0.723$ ), triglyceride ( $p=0.082$ ), HDL ( $\mathrm{p}=0.778)$, LDL $(\mathrm{p}=0.808)$, Hba1c $(\mathrm{p}=0.643)$ levels before and after empagliflozin treatment were not statistically significant $(\mathrm{p}>0.05)$.

Discussion: Patients with type 2 diabetes and heart failure have been reported to have reduced levels of proBNP and Hba1c with SGLT2 inhibition. In addition, it reduces body weight, blood pressure, $\mathrm{CV}$ risk, HF hospitalization. However, in our study, such benefits were not observed in both laboratory and clinical parameters. Large number of patients are needed to research.
\end{abstract}

\section{Introduction}

Type 2 diabetes mellitus (T2DM) incidence is increasing all over the world due to obesity [1]. One of the pathophysiological mechanisms of T2DM is increased glucose reabsorption by kidneys. Heart failure (HF) occurs when the functional impairment develops in the myocardium due to obesity, smoking, coronary heart disease, hypertension [2]. T2DM may concur with HF and cause its development [3]. Some reports suggest that diabetes is found in $40 \%$ of HF patients with reduced and up to $45 \%$ with preserved ejection fraction $[4,5]$.

The sodium-glucose cotransporter 2 (SGLT2) inhibitors induce glycosuria of nearly $60-90 \mathrm{~g} /$ day by blocking SGLT2 mediated proximal tubular glucose reabsorption [6]. SGLT2 inhibitors provide $0.4-0.6 \%$ reduction in glycated hemoglobin (HbAlc) levels in diabetic patients. In addition, they lead to reductions in arterial blood pressure (about 3-6 $\mathrm{mmHg}$ ) and body weight (about $\left.1-2 \mathrm{~kg} / \mathrm{m}^{2}\right)[7,8]$.

The SGLT2 inhibitor, Empagliflozin, improves cardiovascular outcome including death from cardiovascular diseases, nonfatal stroke in patients with T2DM at high risk for cardiovascular events or nonfatal myocardial infarction [9]. Dapagliflozin demonstrated that it provides reduction in the risk of worsening heart failure or death from cardiovascular causes in patients with heart failure independent of the presence of diabetes [10].
EMPA-REG and DAPA-HF trials revealed a reduction in the incidence of acute coronary syndromes $[11,12]$. The excellent pleiotropic effects of SGLT2 inhibitors within the cardiovascular system make these drugs attractive for the treatment of diabetes in patients with HF [13].

We wanted to investigate the effects of empagliflozin in patients who had diabetes mellitus with heart failure.

\section{Materials and methods}

Our study population included 21 type 2 diabetic patients with New York Heart Association (NYHA) classification II to IV with an ejection fraction less than or equal to $40 \%$. All participants involved after signing informed consent. They were enrolled between February 2019 and February 2020. We collected information on age, sex, eGFR, Left ventricular ejection fraction (LVEF) and duration of empagliflozin usage (Table 1). Addition of once daily $10 \mathrm{mg}$ of empagliflozin to their

${ }^{\star}$ Correspondence to: Hatice Ozisik, Department of Endocrinology, Ege University, İzmir, Turkey, E-mail: drhaticege@hotmail.com

Key words: Type 2 diabetes mellitus, SGLT2 inhibitors, heart failure

Received: August 20, 2020; Accepted: September 02, 2020; Published: September 10, 2020 
treatment applied. In addition, we examined NT-proBNP (N-terminal pro-B-type natriuretic peptide), total cholesterol, triglyceride, HDL, LDL, Hbalc levels and NYHA functional classification, furosemide dosages before and after empagliflozin treatment.

The patients were optimally treated with pharmacological therapy for $\mathrm{HF}$ and reduced ejection fraction (HFrEF). Their treatment included angiotensin-converting enzyme (ACE) inhibitor, or angiotensin receptor blocker (ARB) and a beta-blocker, as well as diuretics unless contraindicated or not tolerated.

While the categorical variables were described with frequencies and percentages, descriptive statistics were calculated for continuous variables. The Shapiro-Wilk normality test was used to examine whether the continuous variables were distributed normally. Since the data were not normally distributed, Wilcoxon signed rank test was used to compare the median values of two dependent groups. The Pearson chisquare test were used for the analysis of categorical variables. A value of $\mathrm{P}<.05$ was considered statistically significant. Statistical analyses were performed using IBM SPSS version 25.0 statistical software.

\section{Results}

Table 1 demonstrates the baseline characteristics of the patients. 21 type 2 diabetic patients with NYHA classification II to IV with an ejection fraction less than or equal to $40 \%$ were enrolled, 19 were male (90.5\%). The mean age of the patients was $60 \pm 7.21$ (Male: $59.11 \pm 7.15$; Female: $57.50 \pm 10.60)$. While the eGFR levels of 4 patients $(19.0 \%)$ were between $45-60 \mathrm{~mL} / \mathrm{min} / 1.73 \mathrm{~m}^{2}$, the levels of other patients were above $60 \mathrm{~mL} / \mathrm{min} / 1.73 \mathrm{~m}^{2}$. Before and after empagliflozin treatment, the median of eGFR levels were 77.86 (49.64-126.98) and 73.61 (45.23110.38), respectively. The mean use of empagliflozin was $6.90 \pm 4.38$ months. The mean LVEF in Ecocardiography was $30.52 \pm 9.36 \% .13$ of 21 (\%61.9) patients were using insulin. The mean duration of diabetes for patients was $7.47 \pm 5.77$ years, and the mean duration of heart failure for patients was $50.80 \pm 44.27$ months.

Table 1. Baseline characteristics of patients

\begin{tabular}{|l|c|}
\hline \multicolumn{1}{|l|}{} & $\mathrm{N}=21$ \\
\hline - women & 2 \\
\hline - men & $19(90.5 \%)$ \\
\hline Age (years) & $60 \pm 7.21$ \\
\hline - women & $57.50 \pm 10.60$ \\
\hline - men & $59.11 \pm 7.15$ \\
\hline Duration of Diabetes, years & $7.47 \pm 5.77$ \\
\hline Duration of Heart Failure, months & $50.80 \pm 44.27$ \\
\hline HbA1c, \% & $7.10(5.20-10.90)$ \\
\hline eGFR $<60, \mathrm{~mL} /$ min/1.73 ${ }^{2}$ (45-60) & 4 \\
\hline Left ventricular ejection fraction, $\%$ & $30.52 \pm 9.36$ \\
\hline Duration of empagliflozin usage (months) & $6.90 \pm 4.38$ \\
\hline Furasemid dosage (mg/day) & $40.00(0.00-120.00)$ \\
\hline
\end{tabular}

The demonstration of patients' parameters before and after empagliflozin treatment are shown in Table 2. The difference between pro BNP $(\mathrm{p}=0.205)$, total cholesterol $(\mathrm{p}=0.723)$, triglyceride $(\mathrm{p}=0.082)$, HDL $(\mathrm{p}=0.778)$, LDL $(\mathrm{p}=0.808)$, Hbalc $(\mathrm{p}=0.643)$, eGFR $(\mathrm{p}=0.498)$ levels before and after empagliflozin treatment were not statistically significant $(\mathrm{p}>0.05)$.

During follow-up, none of the patients had urinary tract infections. All patients had had glucosuria except one patient.

\section{Discussion}

Empagliflozin has a potential and competitive inhibition of SGLT2 with the highest selectivity compared with the other SGLT2 inhibitors [14]. Recently, it has been revealed that empagliflozin may reduce infarct size in the isolated mouse hearts [15]. The role of AMPK activation is controversial to explain cardioprotective features of empagliflozin $[15,16]$.

EMPA-REG outcome revealed that patients with T2DM at high risk for cardiovascular events who received empagliflozin had a lower rate of the primary composite cardiovascular outcome [9]. Connelly et al. [17] demonstrated that load-independent effects of empagliflozin contribute to improved cardiac function in experimental heart failure with reduced ejection fraction.

The benefits of SGLT2 inhibitors were independent of plasma glucose lowering. SGLT2 inhibitors improved the myocardial oxygen supply because of this pathophysiological mechanism an increase in hematocrit and hemoglobin could be found [18]. This result is remarkable because anemia and/or a reduction in hematocrit is a welldelineated adverse prognostic factor in heart failure. Furthermore, they have been proposed to have a diuretic effect $[19,20]$. Accordingly, the diuresis induced by SGLT2 inhibition ameliorates the development of LV hypertrophy, provides improved cardiac function independent of loading conditions [17]. In DAPA HF study, independent of glycemic status dapagliflozin improved outcomes in patients with HFrEF. In addition, this study revealed very modest reductions in markers of neurohumoral activation, such as NT-proBNP [10]. There was $48 \%$ reduction in NT-proBNP levels after empagliflozin treatment, but probably because of small number of patients there was no statistically significant difference $(\mathrm{p}=0.205)$.

In addition, SGLT2 inhibitors play a role in HF, diabetic cardiomyopathy, and the rise in keton body formation and consumption [21]. Empagliflozin increases postprandial glucagon concentration and results in a decrease in insulin levels [22]. Consequently, decrease in insulin-to-glucagon ratio in the vena porta stimulates hepatic ketogenesis. Nonetheless, empagliflozin causes a 2-to 3-fold increase in fasting and postprandial levels of $\beta$-hydroxybutyrate [23]. As a result, increased fuel usage of ketone bodies by the heart is related with lower oxygen consumption to provide the same amount of work [21].

Table 2. The demonstration of patients' parameters before and after empagliflozin treatment

\begin{tabular}{|c|c|c|c|}
\hline $\mathbf{N}=\mathbf{2 1}$ & Before empagliflozin treatment & After empagliflozin treatment & p \\
\hline NT-pro BNP,median, ng/L & $1161.00(49.27-13927.00)$ & $614.00(73.53-5963.00$ \\
\hline Total colesterol, $\mathrm{mg} / \mathrm{dL}$ & $134.00(91.00-241.00)$ & $145.00(74.00-240.00)$ \\
\hline Triglyceride, $\mathrm{g} / \mathrm{dL}$ & $108.00(51.00-334.00)$ & $158.00(57.00-507.00)$ \\
\hline HDL, $\mathrm{mg} / \mathrm{dL}$ & $38.00(26.00-45.00)$ & $37.00(25.00-50.00)$ \\
\hline LDL, $\mathrm{mg} / \mathrm{dL}$ & $79.00(33.00-165.00)$ & $75.00(19.00-154.00)$ & 0.723 \\
\hline Hbalc, $\%$ & $7.10(5.20-10.90)$ & $7.20(5.10-9.60)$ & 0.778 \\
\hline NYHA functional classification & II & 0.808 \\
\hline Furosemide dosage, $\mathrm{mg}$ & $40.00(0.00-120.00)$ & 0.643 \\
\hline
\end{tabular}


Although a relationship between glycosuria induced by SGLT2 inhibitors and an increased risk for urinary, particularly genital infections has been demonstrated [24], in our study no patient had urinary or genital infection after treatment.

Several limitations must be considered in our study. We had small number of participants which might potentially conclude in a lack of statistical power to find associations.

\section{Conclusion}

In conclusion, patients with type 2 diabetes and heart failure have been reported to have reduced levels of proBNP and Hbalc with SGLT2 inhibition. Empagliflozin increases postprandial glucagon concentration and results in a decrease in insulin levels, however we did not demonstrate it, this is a limitation of our study. In addition, it reduces body weight, blood pressure, CV risk, HF hospitalization.

However, in our study, such benefits were not observed in both laboratory and clinical parameters. This situation was thought to be due to the low number of patients. Large number of patients are needed to research.

\section{References}

1. Ogurtsova K, da Rocha Fernandes JD, Huang Y, Linnenkamp U, Guariguata L, et al. (2017) IDF Diabetes Atlas: Global estimates for the prevalence of diabetes for 2015 and 2040. Diabetes Res Clin Pract 128: 40-50. [Crossref]

2. Ziaeian B, Fonarow GC (2016) Epidemiology and aetiology of heart failure. Nat Rev Cardiol 13: 368-378. [Crossref]

3. Mentz RJ, Kelly JP, von Lueder TG, Voors AA, Lam CS, et al. (2014) Noncardiac comorbidities in heart failure with reduced versus preserved ejection fraction. $J \mathrm{Am}$ Coll Cardiol 64: 2281-2293. [Crossref]

4. Fonarow GC, Stough WG, Abraham WT, Albert NM, Gheorghiade M et al. (2007) Characteristics, treatments, and outcomes of patients with preserved systolic function hospitalized for heart failure: a report from the OPTIMIZE-HF Registry. $J$ Am Coll Cardiol 50: 768-777. [Crossref]

5. Ather S, Chan W, Bozkurt B, Aguilar D, Ramasubbu K, et al. (2012) Impact of noncardiac comorbidities on morbidity and mortality in a predominantly male population with heart failure and preserved versus reduced ejection fraction. $J$ Am Coll Cardiol 59: 998-1005. [Crossref]

6. Tahrani AA, Barnett AH, Bailey CJ (2013) SGLT inhibitors in management of diabetes. Lancet Diabetes Endocrinol 1: 140-151. [Crossref]

7. Monami M, Nardini C, Mannucci E (2014) Efficacy and safety of sodium glucose cotransport-2 inhibitors in type 2 diabetes: a meta-analysis of randomized clinical trials Diabetes Obes Metab 16: 457-466. [Crossref]

8. Oliva RV, Bakris GL (2014) Blood pressure effects of sodium-glucose co-transport 2 (SGLT2) inhibitors. J Am Soc Hypertens 8: 330-339. [Crossref]

9. Zinman B, Wanner C, Lachin JM, Fitchett D, Bluhmki E, et al. (2015) Empagliflozin, Cardiovascular Outcomes, and Mortality in Type 2 Diabetes. N Engl J Med 373: 2117 2128. [Crossref]
10. McMurray JJV, Solomon SD, Inzucchi SE, Køber L, Kosiborod MN, et al. (2019) Dapagliflozin in Patients with Heart Failure and Reduced Ejection Fraction. $N$ Engl J Med 381: 1995-2008. [Crossref]

11. Fitchett D, Inzucchi SE, Cannon CP, McGuire DK, Scirica BM, et al. (2019) Empagliflozin Reduced Mortality and Hospitalization for Heart Failure Across the Spectrum of Cardiovascular Risk in the EMPA-REG OUTCOME Trial. Circulation 139: 1384-1395. [Crossref]

12. Wiviott SD, Raz I, Sabatine MS, Bonaca MP, Mosenzon O, et al. (2019) Dapagliflozin and Cardiovascular Outcomes in Type 2 Diabetes. Reply. $N$ Engl J Med 380: 347-357. [Crossref]

13. Martens P, Mathieu C, Verbrugge FH (2017) Promise of SGLT2 Inhibitors in Heart Failure: Diabetes and Beyond. Curr Treat Options Cardiovasc Med 19: 23. [Crossref]

14. Grempler R, Thomas L, Eckhardt M, Himmelsbach F, Sauer A, et al. (2012) Empagliflozin, a novel selective sodium glucose cotransporter-2 (SGLT-2) inhibitor: characterisation and comparison with other SGLT-2 inhibitors. Diabetes Obes Metab 14: 83-90. [Crossref]

15. Lu Q, Liu J, Li X, Sun X, Zhang J, et al. (2020) Empagliflozin attenuates ischemia and reperfusion injury through LKB1/AMPK signaling pathway. Mol Cell Endocrinol 501 110642. [Crossref]

16. Andreadou I, Efentakis P, Balafas E, Togliatto G, Davos CH, et al. (2017) Empagliflozin Limits Myocardial Infarction in Vivo and Cell Death in Vitro: Role of STAT3, Mitochondria, and Redox Aspects. Front Physiol 8: 1077. [Crossref]

17. Connelly KA, Zhang Y, Desjardins JF, Nghiem L, Visram A, et al. (2020) Loadindependent effects of empagliflozin contribute to improved cardiac function in experimental heart failure with reduced ejection fraction. Cardiovasc Diabetol 19: 13.

18. Inzucchi SE, Zinman B, Fitchett D, Wanner C, Ferrannini E, et al. (2018) How Does Empagliflozin Reduce Cardiovascular Mortality? Insights from a Mediation Analysis of the EMPA-REG OUTCOME Trial. Diabetes Care 41: 356-363. [Crossref]

19. McMurray J (2016) EMPA-REG - the "diuretic hypothesis". J Diabetes Complications 30: 3-4. [Crossref]

20. Hallow KM, Helmlinger G, Greasley PJ, McMurray JJV, Boulton DW (2018) Why do SGLT2 inhibitors reduce heart failure hospitalization? A differential volume regulation hypothesis. Diabetes Obes Metab 20: 479-487. [Crossref]

21. Ferrannini E, Mark M, Mayoux E (2016) CV Protection in the EMPA-REG OUTCOME Trial: A "Thrifty Substrate" Hypothesis. Diabetes Care 39: 1108-1114. [Crossref]

22. Ferrannini E, Muscelli E, Frascerra S, Baldi S, Mari A, et al. (2014) Metabolic response to sodium-glucose cotransporter 2 inhibition in type 2 diabetic patients. $J$ Clin Invest 124: 499-508. [Crossref]

23. Inagaki N, Kondo K, Yoshinari T, Takahashi N, Susuta Y, et al. (2014) Efficacy and safety of canagliflozin monotherapy in Japanese patients with type 2 diabetes inadequately controlled with diet and exercise: a 24-week, randomized, doubleblind, placebo-controlled, Phase III study. Expert Opin Pharmacother 15: 1501-1515. [Crossref]

24. Wu JH, Foote C, Blomster J, Toyama T, Perkovic V, et al. (2016) Effects of sodiumglucose cotransporter-2 inhibitors on cardiovascular events, death, and major safety outcomes in adults with type 2 diabetes: a systematic review and meta-analysis. Lancet Diabetes Endocrinol 4: 411-419. [Crossref]

Copyright: (C2020 Ozisik H. This is an open-access article distributed under the terms of the Creative Commons Attribution License, which permits unrestricted use, distribution, and reproduction in any medium, provided the original author and source are credited. 